'llu. Revista de Ciencias de las Religiones

ISSN: $1135-4712$

http://dx.doi.org/10.5209/ILUR.57422

\title{
El Hijo del hombre: del libro de Daniel al Nuevo Testamento
}

\author{
Ignacio Sanz Extremeño ${ }^{1}$
}

Recibido: 4 de noviembre de 2016 / Aceptado: 24 de febrero de 2017

Resumen. La expresión bíblica «Hijo del hombre» ha sido, desde el principio del cristianismo, una de las más estudiadas, utilizadas e interpretadas. Este artículo intenta estudiar, desde los textos, el origen de la expresión en el libro de Daniel y su aparición en la Septuaginta, en algunos textos de los llamados apócrifos y en el Nuevo Testamento. Los autores de los evangelios, que escriben en griego y conocen bien el libro de Daniel, relacionan de manera directa el mensaje apocalíptico y mesiánico que aparece en Daniel 7,13, y el uso trivial y cotidiano en arameo de la expresión autorreferencial, dando lugar a la interpretación de «el Hijo del hombre» como título salvífico o mesiánico.

Palabras clave: Hijo del hombre; cristianismo primitivo; Libro de Daniel; Septuaginta; Jesús histórico; ipsissima verba.

\section{[en] Son of Man: from the Book of Daniel to the New Testament}

\begin{abstract}
Son of Man» is one of the most studied, used and interpreted Biblical expressions since the very beginnings of Christianity. This paper tries to provide evidence for the textual origin of this expression, basing on the different studies and interpretations over its occurrences on the Book of Daniel, the Septuagint, some of the so-called Apocrypha and the New Testament. The authors of the Gospels, who wrote in Greek and knew well the Book of Daniel, directly connected an apocalyptic and messianic message, as put forward in Daniel 7:13, with its Aramaic trivial use as an auto-referential designation. Thus, they gave room to a new interpretation of the «Son of Man» expression as a salvific and messianic title.
\end{abstract}

Keywords: Son of Man; Early Christianity; Book of Daniel; Septuagint; Historical Jesus; ipsissima verba.

Sumario. 1. Introducción. 2. El Hijo del hombre en el proceso de la investigación sobre el Jesús histórico. 3. El Hijo del hombre en la Biblia hebrea. 4. Daniel 7,13. 4.1. Las traducciones de Daniel al griego. 4.2. Daniel 7,13. Comparación de los textos griegos y sus diferentes traducciones. 4.2.2. La llamada «Old Greek» (OG). 4.2.2.1. El Papiro 967. 4.2.2.2. El Códice 88, 4.2.3. Teodoción. 4.3. «Uno como Hijo de hombre». 4.3.1. Una figura angélica. 4.3.2. Un símbolo mesiánico. 4.3.3. Una representación de un colectivo. 5. El Hijo del hombre en la Septuaginta. 6. 1 Henoc. 7. 4 Esdras. 8. El Hijo del hombre en el Nuevo Testamento. 8.1 Los dichos sobre el Hijo del hombre. 8.2. Actuación de Jesús en su momento presente. 8.3. Sobre la pasión y resurrección del Hijo del hombre. 8.4. Sobre la parusía del Hijo del hombre. 8.5. El Hijo del hombre en el cuarto evangelio. 9. Conclusión. 10. Bibliografía.

Cómo citar: Sanz Extremeño, I. (2017), El Hijo del hombre: del libro de Daniel al Nuevo Testamento, en 'Ilu. Revista de Ciencias de las Religiones 22, 399-419.

\footnotetext{
1 Universidad Eclesiástica San Dámaso (España).

E-mail: nachosanzext@gmail.com
} 


\section{Introducción}

Pocas expresiones bíblicas han dado lugar a tantos estudios, artículos, libros e incluso congresos internacionales, como la que es el objeto de este artículo.

El objetivo del mismo es estudiar la evolución de un término desde su aparición en arameo en Daniel 7,13 hasta su traducción al griego en sus diversas variantes y su posterior adaptación como título salvífico o mesiánico realizada por los primeros cristianos. Para ello, en primer lugar, analizaré los antecedentes del uso de Hijo del hombre en la Biblia hebrea.

Puesto que, como se verá, los primeros seguidores de Jesús toman la expresión del libro de Daniel, he considerado necesario ahondar en las diversas versiones griegas del texto, examinar sus matices y, por supuesto, investigar el significado propio del Hijo del hombre en el libro de Daniel.

Como resulta verosímil pensar que los primeros cristianos manejaban alguna de las versiones griegas de la Biblia, he realizado un análisis comparativo de las veces que aparece el término en la Biblia hebrea y en la Septuaginta para, de esta manera, poder observar y comentar las discrepancias y las coincidencias que pudiera haber.

Posteriormente he ampliado la búsqueda de la expresión a los llamados textos apócrifos; así, comentaré las apariciones del término en dos textos tan importantes para la literatura apocalíptica y la no canónica como son 1 Henoc y 4 Esdras.

Por último, el estudio del Hijo del hombre en el Nuevo Testamento, de las apariciones de este término y su distinto significado arrojará luz sobre la evolución que se produjo en el uso de la expresión desde Daniel hasta los primeros autores cristianos.

\section{El Hijo del hombre en el proceso de la investigación sobre el Jesús histórico}

A pesar de que, según nos transmiten los Evangelios, Jesús pronunció muchas veces esta expresión refiriéndose a sí mismo, no se nos ofrece en ellos una explicación de qué es lo que significa. De hecho, fuera de los cuatro Evangelios, en los libros que forman parte del Nuevo Testamento solamente encontramos la locución una vez en los Hechos de los Apóstoles, una vez en la Epístola a los Hebreos, y dos veces en el Apocalipsis -en ninguna de estas cuatro ocasiones, como veremos, Jesús se refiere a sí mismo- y ni Pablo ni ninguno de los demás autores la utilizan ni, por lo tanto, podemos encontrar en sus textos ninguna explicación ni indicación del significado que podrían darle. Sin embargo, muchos estudiosos han interpretado el término como algo esencial en la manera que tenía Jesús de referirse a sí mismo y, por tanto, de autodefinirse. Si realmente Jesús lo utilizó para referirse a sí mismo -como esos estudiosos pretenden mostrar-, el examen podría permitirnos tener un mayor conocimiento de lo que pensaba Jesús sobre sí mismo².

La primera interpretación de que tenemos noticia es de Ignacio de Antioquía, en su Carta a los Efesios. Para él, el título subrayaba la naturaleza humana de Jesús, contraponiéndolo -o agregándolo- al título de «Hijo de Dios», que señala su naturaleza divina:

Tomo la base de este apartado de Tejada-Lalinde 2014, 1-7, con algunas modificaciones, actualizaciones y matizaciones. 
$\operatorname{IgEf} 20,2$.

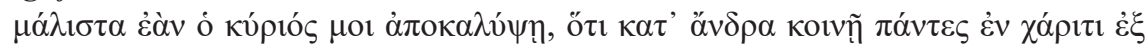

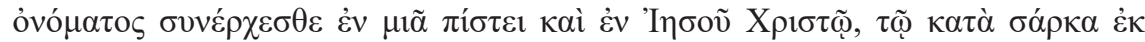

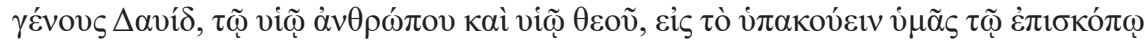

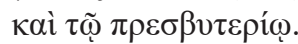

En especial (os mostraré el plan divino) si el Señor me revela que todos como un solo hombre estáis reunidos en común por la gracia de Su nombre en una única fe y en Jesucristo, que es de la estirpe de David en cuanto a la carne, Hijo del hombre e Hijo de Dios, para que vosotros obedezcáis al obispo y al colegio de presbíteros $(\ldots)^{3}$.

A primera vista, esta parece la interpretación más obvia que podría hacer un cristiano y varios padres de la Iglesia coinciden en la explicación. A principios del siglo III, Tertuliano fue el primero que entendió «Hijo del hombre» como un título derivado de Daniel 7,13:

Aduersus Marcionem IV, 10,9-10.

Quid nunc, si ipso titulo filii hominis censetur Christus apud Danielem? Nonne sufficit ad probationem prophetici Christi? Cum enim id se appellat quod in Christum praedicabatur creatoris, sine dubio ipsum se praestat intellegi in quem praedicabatur.

¿Y qué, si Cristo es descrito en Daniel por este mismo título «Hijo del hombre»? ¿No es esto suficiente para probar que Él es el Cristo de la profecía? Pues cuando se llama a Sí mismo lo que se decía del Ungido del Creador, sin duda se ofrece a Sí mismo para ser reconocido como Aquel para el que se reservaba tal título ${ }^{4}$.

Sin embargo, la interpretación genealógica se convirtió en la más influyente desde el principio y a lo largo de toda la Edad Media y continuó siendo la preponderante hasta la reforma protestante. Esto podría deberse al hecho de que los primeros comentaristas se basaron únicamente en la forma griega de la designación -ó viòs

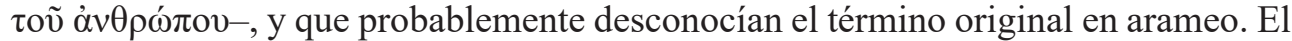
griego podría traducirse por «el Hijo del hombre», como si Jesús estuviera diciendo simplemente que él era hijo de un determinado progenitor. Como señala Burkett ${ }^{5}$, las tres opciones principales entre los primeros estudiosos para adjudicarles la progenitura eran María, José y Adán. María podría ser tomada en consideración porque «hombre» podría tomarse como «ser humano». También podría referirse a José porque, aunque tradicionalmente los cristianos no creían que él era el padre biológico, era, sin embargo, su tutor. Por último, algunos, haciendo hincapié en el artículo determinado, dedujeron que Jesús era el hijo de Adán, la simiente prometida. Esta interpretación genealógica era tan preponderante en la Edad Media que, incluso, algunas versiones de la Biblia transcribían «el hijo de la Virgen» en lugar de «el Hijo del hombre». Sin embargo, este análisis fue siendo sustituido por otras vías de interpretación a partir del siglo XVI, y hacia el XIX los investigadores habían abandonado prácticamente dicha interpretación genealógica del término.

\footnotetext{
Edición: Ehrman 2003. Traducción mía.

Edición: Evans 1972. Traducción mía.

Burkett 2004, 6.
} 
Coincidiendo con la «búsqueda del Jesús histórico» que se inició en el siglo XIX, comenzaron a surgir las dudas respecto a la autenticidad de los «dichos» de Jesús y si él usó realmente el término para referirse a sí mismo. En 1958, Rudolf Bultmann fue uno de los primeros en dividir los apotegmas sobre el Hijo del hombre en tres categorías diferentes que hablan, 1) del que viene, 2) del que padece y resucita, 3) del «Hijo del hombre» que actúa ahora ${ }^{6}$. Con respecto a la primera categoría, Bultmann expuso que Jesús no se refería a sí mismo sino a otra figura posterior y que fue la primitiva comunidad cristiana la que, más tarde, identificó a Jesús con el Hijo del hombre; según esto, esta categoría hablaría, en realidad, de la parusía de Jesús. Sin embargo, considera que los dichos pertenecientes a la segunda categoría son elaboraciones de la primera Iglesia a partir del texto de Daniel y que el Hijo del hombre se utilizó en las alocuciones de la tercera categoría únicamente como una expresión idiomática. Algunos alumnos de Bultmann empezaron la segunda «búsqueda del Jesús histórico» en la década de los años sesenta del siglo pasado -produciéndose casi inmediatamente la tercera búsqueda $-\mathrm{y}$ pronto muchos investigadores se sumaron a las dudas sobre la autenticidad de los dichos, afirmando que en su mayoría se originaron en la primitiva comunidad cristiana. Más recientemente, J. D. Crossan ${ }^{7}$ llegó a la conclusión de que la casi totalidad de los dichos eran creaciones de la iglesia primitiva, con la excepción de la frase que se encuentra en Mateo 8,20, Lucas 9,58 y Q: «Las zorras tienen madrigueras, y los pájaros del cielo nidos; en cambio, el Hijo del hombre no tiene dónde reclinar la cabeza».

La interpretación de que Hijo del hombre no era un título -ya fuera mesiánico o salvífico-, sino una locución de autorreferencia comenzó a ganar terreno. Los investigadores fueron coincidiendo en la idea de que Jesús había hablado arameo y que la expresión aramea pudo haber sido utilizada en «tres formas en el tiempo de Jesús: 1) en el sentido indefinido; 2) en el sentido genérico; y 3 ) en un sentido denominativo o semi-denominativo» ${ }^{8}$. Vermes, por ejemplo, era un defensor de la idea de que Jesús se refería a sí mismo, pero que la expresión aramea no era un título, sino una alocución que él utilizaba para referirse a sí mismo de manera indirecta9.

Un criterio que da unidad a casi todas las corrientes que se incluyeron en la llamada «tercera búsqueda» es que tienden a un criterio de plausibilidad histórica: lo que es plausible en el contexto judío y permite comprender la génesis del cristianismo primitivo, puede ser histórico ${ }^{10}$. En este sentido, se podría decir que sólo porque una frase no encaja con las estructuras propias de un idioma no significa necesariamente que pertenezca a otro. Así, algunos estudiosos llegan a la conclusión de que

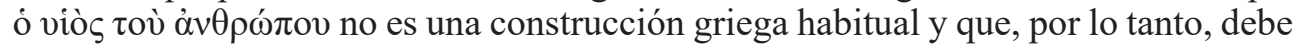
ser arameo o hebreo; sin embargo, es muy posible que no tengan suficientes datos para afirmarlo taxativamente. Por el contrario, sería preciso hacer una investigación mayor sobre la sintaxis de las lenguas involucradas, antes de realizar una aseveración con respecto al origen arameo del Hijo del hombre ${ }^{11}$.

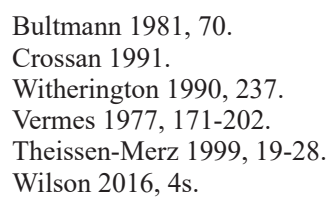




\section{El Hijo del hombre en la Biblia hebrea}

En el Tanaj o Biblia hebrea no hay ninguna aparición de «Hijo de hombre» con artículo determinado. El único caso, sin el artículo, atestiguado en arameo está en Daniel 7,13 -versículo del que nos ocuparemos en el siguiente epígrafe-. En hebreo aparece en 105 ocasiones, también en indefinido. En la Biblia hebrea, la expresión ben adam se utiliza sobre todo para referirse a un individuo específico. Veamos en un cuadro la disposición de las apariciones y su uso ${ }^{12}$ :

\begin{tabular}{|c|c|c|c|}
\hline $\begin{array}{c}\text { Tanaj } \\
\text { Biblia hebrea }\end{array}$ & $\begin{array}{c}\text { Concurrencias de } \\
\text { ben adam }\end{array}$ & $\begin{array}{c}\text { Sentido genérico } \\
\text { o indefinido }\end{array}$ & $\begin{array}{c}\text { Referido a un } \\
\text { individuo específico }\end{array}$ \\
\hline Números & 1 & 1 & 0 \\
\hline Job & 3 & 3 & 0 \\
\hline Salmos & 3 & 3 & 0 \\
\hline Isaías & 2 & 2 & 0 \\
\hline Jeremías & 2 & 2 & 0 \\
\hline Ezequiel & 93 & 0 & 93 \\
\hline Daniel & 2 & 0 & 2 \\
\hline Totales & 106 & 11 & 95 \\
\hline
\end{tabular}

Como puede observarse, en Ezequiel la expresión aparece 93 veces y en todas ellas se refiere específicamente al profeta. En Daniel 8,17, la única aparición en este libro -además de la que da origen al término griego, 7,13-, también se alude concretamente al profeta. Entonces, si ben adam puede utilizarse sin el artículo determinado, en alocuciones claramente definidas, es muy posible que la expresión equivalente en arameo funcione de la misma manera. Ya que, como vemos, en la Biblia hebrea no aparece en ninguna ocasión con el artículo determinado, no parece extraño que no exista tampoco en su traducción al griego, la Septuaginta; del mismo modo, estas expresiones hebreas cuando tienen un sentido genérico o indefinido son fielmente traducidas al griego ${ }^{13}$.

La tradición bíblica no define a los hombres por su esencia, como hacían los griegos -cuerpo, alma-, sino que lo hace por su linaje tanto familiar como social, de un modo histórico. Así, «judío» es aquél que nace de un judío -más concretamente, de una mujer judía- y, por tanto, hombre es todo aquél que nace de otro hombre -o mujer-: de esta manera, cada ser humano es un «Hijo de hombre». Esto se señala muy claramente en el libro de Ezequiel, especialmente en algunos comienzos de capítulos: Ez 2,1; 3,1; 4,1.

Tejada-Lalinde 2014, 13.

Tejada-Lalinde 2014, 12-14. 


\section{Daniel 7,13}

Dado que el interés del presente artículo es comprobar cómo se recoge la expresión semítica en sus traducciones al griego y puesto que para la mayoría de los estudiosos los primeros cristianos toman la alocución del libro de Daniel, será interesante analizar este texto con mayor detenimiento.

\subsection{Las traducciones de Daniel al griego}

Las versiones griegas del Libro de Daniel -como sucede también con las de la Peshitta siriaca y la Vulgata Latina- contienen, además de los doce capítulos que se encuentran en el Texto Masorético original (MT), las llamadas Adiciones: la Oración de Azarías y el Cantar de los Tres Judíos, así como las historias de Susana, Bel y el Dragón. La historia textual de estas versiones griegas es muy compleja. Existen dos tradiciones textuales distintas: el libro de Daniel de la LXX o Antiguo Griego (= OG-Dn) y el llamado Daniel de Teodoción (= Th-Dn). La relación existente entre OG-Dn y Th-Dn es un tema cuya investigación aún no se ha cerrado ${ }^{14}$.

\subsection{Daniel 7,13. Comparación de los textos griegos y sus diferentes traducciones}

\subsubsection{La llamada «Old Greek» (OG)}

Aunque es importante tener en cuenta las diferencias existentes entre el original hebreo-arameo y las versiones griegas, así como el tratar de investigar las razones de estas diferencias, también merece la pena examinar la interpretación que nos proporciona OG, ya que es un testimonio importante de una tradición específica del libro de Daniel, sobre todo si tenemos en cuenta que en muchos sentidos, cada traducción supone una interpretación del texto ${ }^{15}$.

De este texto conservamos dos versiones que, en el caso de los versículos que nos ocupan, presentan algunas variantes.

\subsubsection{El Papiro 967}

El Papiro 967 es un manuscrito bíblico datado en el siglo III d.C., que fue descubierto en 1931. Es notable porque contiene fragmentos del texto griego original del Libro de Daniel, que fue reemplazado por un texto revisado a finales del siglo IV. Nos han llegado 59 páginas manuscritas, que se encuentran repartidas en cinco lugares: la Chester Beatty Library (Dublín), la Biblioteca de la Universidad de Princeton, la Biblioteca de la Universidad de Colonia, la Abadía de Santa María de Montserrat (Barcelona) y la Fundación Pastor de Estudios Clásicos (Madrid).

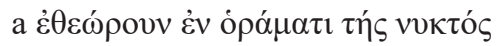

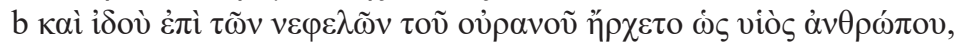

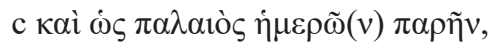




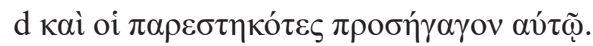

Contemplaba entre las visiones de la noche y he aquí que sobre las nubes del cielo venía uno como Hijo de hombre y llegaba como anciano de los días y los que estaban presentes le servían ${ }^{16}$.

\subsubsection{El códice 88}

El Codex Chisianus 88 (también conocido como Chigianus o «MS $88 »$ ) es un manuscrito del siglo IX, editado por primera vez en 1772. Contiene lo que sobrevivió como única versión original de la Septuaginta del Libro de Daniel, hasta el descubrimiento del Papiro 967. El manuscrito probablemente deriva de la recensión de la Septuaginta hecha por Orígenes aproximadamente en 240.

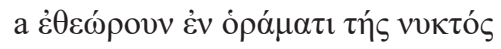

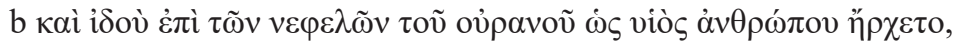

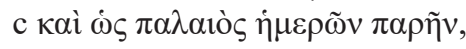

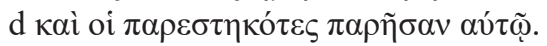

Contemplaba entre las visiones de la noche y he aquí que sobre las nubes del cielo venía uno como Hijo de hombre y llegaba como anciano de los días y los que estaban presentes se le acercaban.

\subsubsection{Teodoción}

Teodoción fue un erudito judío de época helenística que tradujo la Biblia hebrea al griego aproximadamente en el 150 d.C. Ya en el siglo II el texto es citado en el Pastor de Hermas y en el Diálogo con Trifón de Justino.

La traducción de Teodoción fue tan copiada en la iglesia paleocristiana que su versión del libro de Daniel prácticamente superó a la de la Septuaginta. San Jerónimo (en su prólogo a Daniel, 407 d.C.) registra el rechazo a la versión de la Septuaginta del libro de Daniel.

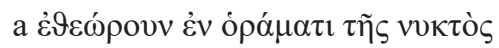

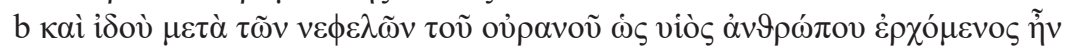

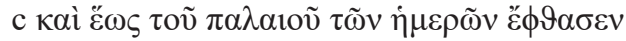

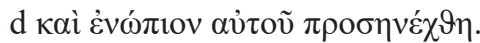

Contemplaba entre las visiones de la noche y he aquí uno como Hijo de hombre que venía entre las nubes del cielo y llegaba ante el anciano de los días y fue llevado ante su presencia.

\section{3. «Uno como Hijo de hombre»}

Como indica Reynolds ${ }^{17}$, la OG presenta al «uno como Hijo de hombre» como alguien asimilado al «anciano de los días» de cuatro maneras:

\footnotetext{
16 Para todas las versiones griegas del Libro de Daniel, tomo la edición de Ziegler-Munnich 1999; las traducciones son mías.

17 Reynolds 2008, 77.
} 
1. Llega «como» ( $\dot{\omega})$ ) el anciano de los días.

2. Aparece «sobre» (غ่)ì) las nubes del cielo.

3. Recibe la asistencia de los presentes, lo que sugiere el culto dado a Dios.

4. Se le acercan los que estaban presentes ante el anciano de los días ${ }^{18}$.

Examinando el retrato que se hace del «uno como Hijo de hombre», se ve que la OG lo describe como alguien similar al anciano de los días, pero no hay ninguna indicación de equivalencia o identificación; es decir: no parece que nos indique que se trate de la misma persona, sino de dos personas con características asimiladas. De hecho, la entrega de la autoridad al «uno como Hijo de hombre» implica que la condición humana de esta figura es diferente de la del anciano de los días ${ }^{19}$. En este retrato también se sugiere que tiene una naturaleza mesiánica. Esto se ve más claramente en el siguiente versículo, Dn 7,14 -en la versión de OG-, en el que se habla de la autoridad regia que recibe, en el hecho de que su reino nunca pasará y en su diferenciación de los santos del Altísimo:

Y se le dio a él una autoridad real, y todas las naciones de la tierra por linajes y toda la gloria estaba a su servicio. Y su autoridad es autoridad eterna que ya no será suprimida, y su reino ya no se destruirá.

Como indica Wilson ${ }^{20}$, aunque son muchas las opiniones que se han vertido acerca del significado de la expresión, solamente tres interpretaciones merecen un análisis más detallado; esto se ve aún más claro si partimos de las propuestas que ya hizo Collins ${ }^{21}$ y que, como ocurre en otras investigaciones de este estudioso, se han convertido en clásicas.

\subsubsection{Una figura angélica}

Según Russell ${ }^{22}$, la explicación más simple es la más satisfactoria. Afirma que aquél «como un hijo de hombre» es un ángel y, en concreto, Miguel, que es el encargado de la protección de Israel. Según él, sería en un desarrollo posterior -en 1 Henoc y en la tradición cristiana- cuando se convertiría en una figura mesiánica.

Es cierto que los ángeles son descritos en muchas partes con una apariencia humana, especialmente en los textos apocalípticos: (Dn 8,15; 10,18), como un hombre (Dn 9,21; 10,5; 12,6-7) y a semejanza de los Hijos de los hombres (Dn 10,16). Pero también Daniel es llamado Hijo del hombre (Dn 8,17), y la frase de origen arameo «como Hijo de hombre» no se usa en ningún otro sitio más que en Daniel 7,13. La gran debilidad argumental que tiene la interpretación angélica es que en ningún sitio del canon hebreo se da poder y culto a los ángeles, como sí recibe el «uno como Hijo de hombre» $(\text { Dn 7,14 })^{23}$.

\footnotetext{
18 Aunque una comparación exhaustiva se escaparía a los límites del presente estudio, conviene indicar que, en el caso de Teodoción, el «uno como Hijo del hombre» llega «entre» las nubes, se presenta «ante» el anciano de los días y no se hace mención de los que estaban presentes.

19 Reynolds 2008, 79.

Wilson 2016, 11.

Collins 1993, 304-310.

Russell 2005, 67.

Shepherd 2006, 103.
} 


\subsubsection{Un símbolo mesiánico}

En las imágenes bíblicas tradicionales, el jinete que está «sobre»o «entre» las nubes suele ser identificado con Yahveh. Esta identificación se explica fácilmente porque una imagen similar se puede constatar en la mitología ugarítica, en la que Baal es descrito a menudo como un jinete de las nubes. Sin embargo, Baal está subordinado a El, que es el padre de los dioses y de los seres humanos. Aplicando la analogía al texto que nos ocupa, si el que viene con las nubes es Baal, el anciano de los días sería El; es decir: el anciano de los días sería Yahveh y el Hijo del hombre el mesías, puesto que está subordinado a Dios. Siguiendo una argumentación similar, Reynolds sostiene que, según la lectura de la OG, la figura del Hijo del hombre es claramente mesiánica ${ }^{24}$.

\subsubsection{Una representación de un colectivo}

Probablemente esta sea la teoría más defendida por los estudiosos ${ }^{25}$ : la idea de que el Hijo del hombre debe ser interpretado colectivamente como el pueblo de Israel. Según esto, si las cuatro bestias que describe Daniel son la representación de cuatro reinos o pueblos, el Hijo del hombre sería la representación del quinto y definitivo: el pueblo elegido, que fue menospreciado y perseguido, pero más tarde devuelto a su antigua gloria. Esta interpretación fue propuesta por $\operatorname{Dodd}^{26}$ y fue compartida y ampliada por Russell, que afirmó que el Hijo del hombre tiene un sentido colectivo y que «representa el reino de Dios entregado al pueblo de Dios» ${ }^{27}$.

\section{El Hijo del hombre en la Septuaginta}

El nombre de Septuaginta o Biblia de los setenta hace referencia al número de los eruditos -setenta o setenta y dos- que, según la tradición, tradujeron la Torá judía en tiempos del rey Ptolomeo II Filadelfo (285-246 a.C.). En un principio, la traducción abarcó sólo el Pentateuco, pero posteriormente el nombre pasó a designar todos los escritos que integran la Biblia griega ${ }^{28}$. Los primeros cristianos la emplearon como Biblia oficial para la evangelización y así, mediante la traducción a otras lenguas, el influjo de la Septuaginta se extendió hasta los confines del Imperio romano.

Dado que el punto de partida es comprobar cómo pasó la expresión Hijo de hombre del arameo del libro de Daniel a su traducción griega, compararé las ocasiones en las que aparece la alocución en la Biblia hebrea y en la Septuaginta:

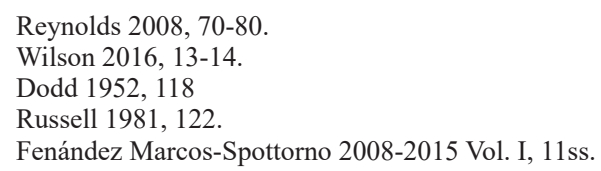




\begin{tabular}{|c|c|c|}
\hline & Tanaj Biblia hebrea & Septuaginta Biblia griega \\
\hline Números & 1 & 1 \\
\hline Isaías & 2 & 1 \\
\hline Jeremías & 2 & 2 \\
\hline Ezequiel & 93 & 86 \\
\hline Salmos & 3 & 4 \\
\hline Job & 3 & 3 \\
\hline Daniel & 2 & 2 \\
\hline Judit & 0 & 1 \\
\hline Eclesiástico & 0 & 1 \\
\hline Totales & 106 & 102 \\
\hline
\end{tabular}

Como se aprecia en el cuadro, además del baile de cifras que se produce en algunos de los libros -en Salmos y, especialmente, en Ezequiel-, llama la atención que el término aparece en la Septuaginta en dos lugares en los que no aparecía en la Biblia Hebrea, en libros originalmente compuestos en época helenística, alrededor del siglo II a.C.

El pasaje del libro de Judit está inserto en el discurso que pronuncia ante los ancianos de la ciudad y contiene una cita de Números, pero ordenada de distinta manera ${ }^{29}$; de hecho, podemos comparar ambos textos con la traducción de la Biblia hebrea:

Nm 23,19 (Biblia hebrea).

No es el hombre para mentir, ni Hijo de hombre para arrepentirse.

¿Es El quien dice y no hace, o quien habla y no realiza? ${ }^{30}$

Nm 23,19 (LXX).

No como al hombre se engaña a Dios,

ni como al Hijo del hombre se le puede amenazar ${ }^{31}$.

Jdt 8,16 (Biblia hebrea).

Pero vosotros no hipotequéis los planes del Señor, nuestro Dios, porque no hay que amenazar ni juzgar a Dios como a un hombre.

Jdt 8,16 (LXX).

Pero vosotros no hipotequéis los planes del Señor nuestro Dios, porque no hay que amenazar a Dios como a un hombre, ni juzgarlo como a un Hijo de hombre.

29 Corley 2015, 228.

30 Para todos los textos de la Biblia Hebrea, tomo la traducción de Cantera-Iglesias 1975.

31 Para todos los textos de la Septuaginta, tomo la traducción de Fernández Marcos-Spottorno 2008-2015. 
Por su parte, la cita del Eclesiástico -o Sabiduría de Ben Sirakh- está incluido en un apartado en el que «se formulan máximas sapienciales sobre las relaciones entre Dios y el hombre, sobre la conducta del sabio y del necio y se dan instrucciones sobre el hablar ${ }^{32} \gg$ :

\section{Si 17,30 .}

No pueden existir todas las cosas entre los hombres, porque el Hijo del hombre no es inmortal.

Como se ve, en ambos casos el significado que podríamos dar a «Hijo de hombre» es, simplemente, el de «ser humano, hombre», sin ninguna connotación mesiánica que pudiera haber sido heredada del libro de Daniel.

\section{1 Henoc}

El libro que conocemos como Henoc etiópico o 1 Henoc es en realidad un conjunto de textos de épocas dispares, fusionados en un volumen por una mano desconocida, parapetada, como suele ser habitual, bajo el nombre de un personaje ilustre ${ }^{33}$.

La práctica totalidad de los estudiosos está de acuerdo en la división de 1 Henoc en cinco secciones, que formarían una especie de «pentateuco», lo que era habitual en algunas colecciones de textos judías; a estas se añadiría una introducción y una conclusión. En el segundo de estos libros - conocido como Libro de las parábolas o Similitudes-aparece la expresión Hijo del hombre en 14 ocasiones. Además de estas citas, la visión que se narra en Daniel 7 es interpretada en los capítulos 46 y 47:

1Hen 46,1-2.

Allí vi al que posee el «Principio de días», cuya cabeza es blanca como lana, y con él vi a otro cuyo rostro es como de apariencia humana, mas lleno de gracia, como uno de los santos ángeles. Pregunté a uno de los santos ángeles, que iba conmigo y me mostraba todos los secretos, acerca de aquel Hijo del hombre, quién era, de dónde venía y por qué iba con el «Principio de días» ${ }^{34}$.

1 Hen 47,3.

En esos días vi al «Principio de días» cuando se sentó en su trono de gloria y los libros de los vivientes fueron abiertos ante él. Y toda la cohorte del cielo superior y su cortejo estaba en pie ante él.

En el texto, la manera en la que se refiere al Hijo del hombre no hace suponer que fuera un título reconocible, sino que parece otra manera de referirse a aquel «cuyo rostro es como de apariencia humana», mientras al mismo tiempo alude a Daniel ${ }^{35}$.

A pesar de su vínculo con Daniel, el Hijo del hombre que aparece en 1 Henoc va más allá de su faceta humana: el libro fue escrito para articular la visión del mundo

\footnotetext{
Fernández Marcos-Spottorno 2008-2015 Vol. III, 552.

Díez-Macho 1982, 13.

Los textos de 1 Henoc corresponden a la traducción de Corriente-Piñero 1984.

Collins 2010, 197.
} 
que tenía un determinado grupo de judíos del siglo I d.C. La figura es aquí el contrapunto celestial de los justos en la tierra. Mientras ellos son oprimidos y humillados, él está entronizado y ensalzado; cuando se manifieste en el juicio escatológico, también los justos serán ensalzados ${ }^{36}$. Así, el autor del Libro de las parábolas parte del libro de Daniel para desarrollar su propia expresión de la fe y la esperanza de los justos; mientras que no ofrece ninguna razón para que podamos ver otro origen a la expresión más que el libro de Daniel, muestra cómo éste inspiró una figura salvadora celeste dentro del judaísmo del primer siglo de nuestra era. Como bien señala Adams $^{37}$, en el Libro de las parábolas se da al Hijo del hombre un papel escatológico: su función principal es la de juez en el juicio final, sentado en el trono divino ( $c f r .45,3 ; 51,3 ; 55,4 ; 61,8 ; 62,2-5 ; 69,29)$; él juzga las obras de los ángeles $(61,8)$, las de los reyes y los gobernantes de la tierra $(62,3-12)$ y las de los pecadores $(45,2-$ 3 ). Tras la sentencia y su cumplimiento, el elegido gobernará sobre unos transformados cielo y tierra $(45,4-5)$.

Generalmente se acepta que el Hijo del hombre se identifica con Henoc al final del Libro de las parábolas. En 71,14, Henoc es recibido por un ángel en su ascensión al cielo y le dice:

«Tú eres el Hijo del hombre que naciste para la justicia; ella ha morado en ti, y la justicia del «Principio de días» no te dejará».

Sin embargo, como afirma Collins en varios artículos, «la supuesta identificación (de Henoc con el Hijo del hombre) sigue siendo problemática ${ }^{38}$.

\section{4 Esdras}

Esdras fue un escriba que, probablemente, vivió durante el reinado de Artajerjes II, cuya fama de restaurador de las costumbres le convirtió en protagonista de varias leyendas y libros piadosos. El llamado Libro IV de Esdras o 4 Esdras comprende los capítulos 3 al 14 del texto latino conocido como $4^{\circ}$ de Esdras.

La obra se sitúa en Babilonia, el año 30 después de la destrucción de Jerusalén, es decir, el 557 a.C. ${ }^{39}$

Aunque el autor de 4 Esdras no emplea explícitamente la frase «Hijo del hombre», es evidente su relación con la imaginería de Dn 7,13 en el retrato de la figura salvífica ${ }^{40}$ :

4Esd 13,2-3.

$\mathrm{Y}$ vi que se levantaba un viento del mar de manera que agitaba todas sus olas. [Y miré y vi que este viento hacía que una figura como de hombre saliera del corazón del mar $]^{41}$.

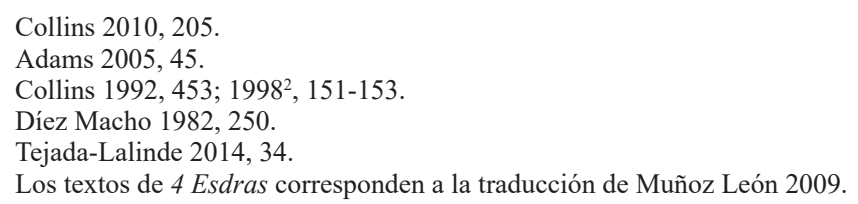


De hecho, el mismo autor se encarga de dejar claro que conoce y utiliza el texto de Daniel:

4Esd 12,11-12.

El águila que has visto subir del mar es el cuarto reino de la visión que tuvo tu hermano Daniel. Pero a él no se le interpretó en los términos en los que yo te lo interpreto y te he interpretado.

La figura que podríamos relacionar con el Hijo del hombre tiene un sesgo mucho más mesiánico que en el libro de Daniel y que, incluso, en 1 Henoc. Por ejemplo, en los capítulos 11 y 12 aparece un león, que es interpretado de forma explícita como «el ungido que el Altísimo reservó para el fin (de los días)» (12,32). En los versículos siguientes describe la escena del juicio que, a diferencia de lo que se narraba en el Libro de las parábolas, se lleva a cabo en la tierra y que se asocia con la restauración del pueblo judío ${ }^{42}$ :

4Esd 12,33-34.

Los llevará vivos primeramente a juicio, y una vez que les haya reprochado, los aniquilará. Pero librará al resto de mi pueblo con misericordia, a los que fueron salvados dentro de mis confines, y los alegrará hasta que llegue el fin, el día del juicio del que te he hablado desde el principio.

Según Vermes, no podemos deducir del texto un uso de «Hijo de hombre» como un título mesiánico, como aparecerá posteriormente: «todo lo fechable de 4 Esdras es sin duda posterior al año 70 d.C., y está condicionado por la destrucción del Templo. Su testimonio es más relevante, en consecuencia, para la comprensión de los orígenes del cristianismo que para la de Jesús y su época» ${ }^{43}$.

\section{El Hijo del hombre en el Nuevo Testamento}

En los evangelios sinópticos, «Hijo del hombre» es un título usado para caracterizar a Jesús, aunque la mayor parte de las ocasiones aparece en su propio discurso. Debido a sus características especiales, las veces en las que aparece el término en el Cuarto Evangelio se estudiarán en un epígrafe aparte. En el siguiente cuadro se muestra el número de veces que aparece la expresión en cada uno de los $\operatorname{libros}^{44}$ del Nuevo Testamento. La ordenación de los textos está realizada cronológicamente, por la importancia que pueda tener para la evolución del término; dado que lo relativo a la datación de los textos del Nuevo Testamento es controvertido, he adoptado la estimación media que se extrae del reciente artículo de Porter ${ }^{45}$.

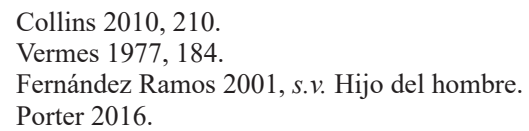




\begin{tabular}{|c|c|}
\hline Texto & Ocurrencias \\
\hline Evangelio de Marcos & 14 \\
\hline Evangelio de Mateo & 30 \\
\hline Evangelio de Lucas & 25 \\
\hline Hechos de los Apóstoles & 1 \\
\hline Epístola a los hebreos & 1 \\
\hline Evangelio de Juan & 13 \\
\hline Apocalipsis & 2 \\
\hline
\end{tabular}

\subsection{Los dichos sobre el Hijo del hombre}

$\mathrm{Si}$, como estamos viendo, la expresión «Hijo del hombre» había ido tomando importancia y se había ido tiñendo de significado mesiánico, resulta extremadamente curiosa «la falta de impacto de la expresión en los contemporáneos de Jesús. Lejos de ser tratado como un misterio, el más problemático de todos los problemas del Nuevo Testamento (...) no despertó ni entusiasmo ni hostilidad entre amigos y adversarios $\rangle^{46}$.

Son varios los estudiosos que coinciden en dividir las apariciones en el NT Hijo del hombre en tres categorías o clases ${ }^{47}$ :

1. Los referidos a la actuación de Jesús en su momento presente.

2. Los que hablan de la pasión y la resurrección del Hijo del hombre.

3. Los que se refieren a la parusía del Hijo del hombre.

En algunas ocasiones estas categorías son, de hecho, impuestas arbitrariamente a los textos. Algunos de los dichos no encajan perfectamente en ninguno de sus tres grupos. Por ejemplo, la última bienaventuranza en Lucas habla de los cristianos que son condenados al ostracismo a causa del Hijo del Hombre (Lc 6,22-23). ¿La condena es por su lealtad al Jesús terrenal o por su esperanza en el Hijo celestial del hombre? En Lucas 17,22 Jesús les dice a los discípulos que vendrán días en los que desearán ver al Hijo del Hombre y no lo verán. En un contexto post-pascual, este versículo se refiere a Jesús como el Hijo terrenal del Hombre por cuya ausencia ahora están de luto, como lo que se dice en Lucas 5,35, «Vendrán días cuando les sea arrebatado el esposo, y entonces ayunarán en aquellos días.» Pero también podría entenderse como referido a la parusía, que vendrá «en el tiempo del Hijo del Hombre» $(\operatorname{Lc} 17,26)^{48}$.

46 Vermes 1977, 172.

47 Cf. Bultmann 1981, 70; Piñero 2006, 207ss; Naseri-Naseri 2013, 192; Kirchhevel 1999, 181; Pikaza 2007, 30s y 450; Fernández Ramos 2001, s.v. Hijo del hombre; Vermes 1977, 188.

48 Yarbro Collins, 1996, 144. 
Existen cuatro ocasiones en las que quien lo pronuncia no es Jesús y las cuatro se dan fuera de los evangelios. La primera está en el libro de los Hechos de los Apóstoles y corresponde a la respuesta que da Esteban a sus martirizadores: Hch 7,56.

La segunda es de la Epístola a los Hebreos y, en realidad, recoge una cita del libro de los Salmos 8,5-7: $\mathrm{Hb} 2,6$.

Las dos veces que aparece el término en el Apocalipsis tienen una evidente procedencia de Daniel 7,13: Ap 1,13 y 14,1449.

Para una mejor comprensión, voy a seguir la clasificación indicada más arriba a la hora de exponer las características de las distintas ocasiones en las que aparece la alocución en los evangelios sinópticos y, posteriormente, comentaré las apariciones de la locución el en cuarto evangelio, por sus características especiales.

\subsection{Actuación de Jesús en su momento presente}

Parece que en estos textos la expresión es utilizada como circunloquio para referirse a sí mismo con modestia, sin decir «yo» ${ }^{50}$. Así, por ejemplo en Mc 10,45 (par.: Mt 20,28).

Incluso en esta otra ocasión-Mc 2,27-28 (par.: Mt 12,8; Lc 6,5)-, en la que Jesús se autoproclama como dueño del sábado, la mención al Hijo del hombre no es más que una manera de referirse a sí mismo, que cobra sentido si se une al versículo anterior, sin sacarla de contexto. Al mismo tiempo, resulta interesante recalcar que existe una norma rabínica según la cual, si hay que elegir, más vale salvar la vida humana que las leyes del sábado ${ }^{51}$.

También en Mc 14,21 (par.: Mt 26,24), que se encuentra inserta en el relato de la cena pascual, queda patente que el término es utilizado como autorreferencia.

Una de las citas por las que parece más claro el significado autorreferencial del término es aquella en la que Jesús pregunta quién dice la gente que es él. Mientras Mateo pone en boca de Jesús «Hijo del hombre», los paralelos en Marcos y Lucas dicen simplemente «yo»: Mt 16,13; Mc 8,27; Lc 9,18.

Esto mismo -solo que al contrario-sucede en un pasaje que analizaremos más adelante: Mc 8,38 (par.: Mt 10,33; 16,27; Lc 12,8); en esta ocasión es Mateo el que utiliza el pronombre personal, mientras los otros dos hablan de Hijo del hombre.

La siguiente cita es, en realidad, la primera vez que aparece el término en el Evangelio de Marcos y en ella parece claro que Jesús se refiere a sí mismo, aunque se arrogue el poder de perdonar los pecados; según Vermes, si hubiese dicho «yo tengo autoridad para perdonar los pecados», habría parecido inmodestia ${ }^{52}$ : Mc 2,1011 (par.: Mt 9,6; Lc 5,24).

Así, vemos que Jesús es simplemente un hombre como los demás, que come y bebe y no tiene dónde reclinar la cabeza: Mt 11,19 (par.: Lc 7,34) y Mt 8,20 (par.: Lc 9,58).

\footnotetext{
49 James D. G. Dunn estudia exhaustivamente las citas de Daniel que están presentes en los textos de los Evangelios y del Apocalipsis de Juan. Véase Dunn 2001, 529-536.

P0 Piñero 2006, 207.

51 Vermes 1977, 192.

52 Vermes 1977, 191.
} 


\subsection{Sobre la pasión y la resurrección del Hijo del hombre}

Algunos autores consideran que los ejemplos que se incluyen en este apartado son uaticinia ex euentu y, por lo tanto, son elaboraciones posteriores realizadas por los primeros cristianos. Como afirma Piñero: «Muchos críticos católicos admiten este argumento, aunque en el fondo late en él una crítica racionalista: no es admisible que Jesús, como hombre que era, pudiera predecir el futuro» ${ }^{53}$. Este tipo de textos queda bastante claro con el siguiente caso: Mc 8,31 (par.: Lc 9,22).

El versículo anterior está inserto en el relato del primer anuncio de la Pasión; curiosamente, en el segundo y tercer anuncio vuelve a usar la misma expresión: Mc 9,31 (par.: Mt 20,18; Lc 9, 44) y Mc 10,33 (par.: Lc 18,31).

En otras ocasiones, se identifica con «pecadores» a aquellos a los que se va a entregar al Hijo del hombre: los sumos sacerdotes y los escribas tendrán en sus manos el destino del Hijo del hombre: Mc 14,41 (par.: Mt 17,22; Lc 24,7).

En el episodio de la transfiguración de Jesús vuelve a mencionar la resurrección del Hijo del hombre y lo enlaza con Elías, como personaje ya resucitado; pero, a la vez, une a Elías con Juan el Bautista, como precursor del Hijo del hombre: Mc 9,913 (par.: Mt 16,9-13).

\subsection{Sobre la parusía del Hijo del hombre}

En la tradición sinóptica no encontramos ninguna palabra de Jesús en la que indique que regresará en un futuro inminente ${ }^{54}$. Por eso los ejemplos de esta categoría se entienden por algunos investigadores como referencias por parte de Jesús a un personaje celeste diferente de sí mismo, que llegará tras él y que será intermediario en el Juicio Final ${ }^{55}$. En algunas ocasiones hay que forzar un poco la interpretación para concluir que Jesús no está hablando de sí mismo: Mc 8,38 (par.: Mt 10,33; 16,27; Lc $12,8)$. Como indica J. Schröter ${ }^{56}$, en esta cita es la primera vez que aparece el término Hijo del hombre con la función de juez apocalíptico.

Resulta llamativo que «Hijo del hombre» nunca se refiera a la vez a la pasión y a la parusía. Según Piñero ${ }^{57}$, la traducción errónea al griego de la frase aramea hizo que se relacionara con el personaje de Daniel 7,13 y Marcos -y posteriormente los otros evangelistas- mezcló las distintas tradiciones con la mesiánica y las adjudicó en su totalidad a Jesús.

La parábola de la cizaña aparece solamente en Mateo. En ella resulta evidente que el Hijo del hombre es un personaje secundario y que está en la interpretación de la parábola, hecha por la primitiva iglesia ${ }^{58}$ : Mt 13,37-41. Este pasaje representa al Hijo del Hombre como Juez. La referencia al «Reino de su Padre» muestra que él es el agente de Dios en el ejercicio del juicio. La representación del Hijo del hombre como juez también se encuentra en el Libro de las parábolas de Henoc (1 Hen 46,4$8 ; 69,29)$

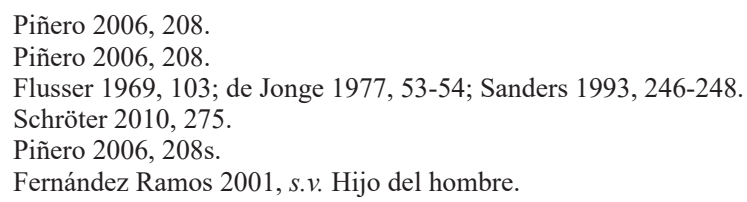


En este apartado cabe citar los textos en los que se pone de manifiesto la vinculación de la expresión, en origen autorreferencial, con el pasaje mesiánico de Daniel 7,13; esto es algo que cualquier judío medianamente cultivado de la época conocía perfectamente: Mc 14,62 (par.: Mt 24,30; Lc 21,27) y Mt 26,64. También el pasaje de Lc 12,8-9 comparte con Daniel 7 las características de la escena celestial, el escenario forense y la presencia del Hijo del Hombre. Es probable que Daniel 7 tuviera una influencia en la creación de este dicho ${ }^{59}$.

Tanto en el texto de Mateo que acabamos de ver como en el siguiente de Lucas, se empieza a ver la tensión existente entre el «ya» y el «todavía no» de la parusía; en ambos se dice que el Hijo del hombre será visible en su esplendor «desde ahora»: Lc 22,69.

En otras ocasiones, el Hijo del hombre «aparece como un personaje simbólico, que representa al ser humano, visto en su culminación, desde el fin de los tiempos ${ }^{60}$ : Mc 13,26 (par.: Mt 24,30; Lc 21,27).

A veces, la esperanza escatológica es referida a un evento anterior, conocido por todos, para ejemplificar la desolación que precederá al juicio final. Al mismo tiempo, se advierte de la inminencia de la parusía del Hijo del hombre y del desconocimiento del momento exacto: Mt 24,37-44 (par.: Mc 13,32-37; Lc 17,26-30; 34-40).

En los ejemplos anteriores, resulta curioso que, mientras que Mateo alude al diluvio, Lucas lo hace a la destrucción de Sodoma y Gomorra y Marcos, sin embargo, no pone ningún ejemplo.

Del mismo modo se relaciona al Hijo del hombre con Jonás: debería ser para sus contemporáneos lo mismo que Jonás fue para los ninivitas ${ }^{61}$ : Mt 12, 39-40 (Lc 11,30).

Este es otro de los casos de uaticinia ex euentu evidentes: «prefigura» la resurrección de Jesús, cuando el texto fue compuesto mucho después.

También se enlaza la figura del Hijo del hombre con la del Espíritu Santo, lo que supone una tensión entre la fase terrena y la celeste de Jesús ${ }^{62}$ : Mt 12,32 (par.: Lc 12,10).

Por último, Jesús «anuncia su función escatológica: quien le niegue en el mundo será negado por el Hijo del humano cuando venga en la gloria del Padre para el juicio» ${ }^{63}$ : Mt 16,31.

La representación del Hijo del hombre como juez es más clara en la respuesta de Jesús a la pregunta de Pedro: «Ya lo ves, nosotros lo hemos dejado todo y te hemos seguido; ¿qué recibiremos, pues?». La respuesta de Jesús incluye la frase «el trono de su gloria», que también aparece en las El libro de las parábolas de Henoc con referencia al trono del «Hijo del Hombre», es decir, la figura de Daniel 7 que en el libro de Henoc representan como un mesías preexistente y celestial ${ }^{64}$.

\footnotetext{
Yarbro Collins-Collins 2008, 155.

Pikaza 2007, 31.

Fernández Ramos 2001, s.v. Hijo del hombre.

Fenández Ramos 2001, s.v. Hijo del hombre.

Pikaza 2007, 450.

Yarbro Collins-Collins 2008, 152.
} 


\subsection{El hijo del Hombre en el cuarto Evangelio}

En la presentación del Hijo del hombre que realiza el autor del Evangelio de Juan no se pueden distinguir claramente las tres categorías que hemos utilizado para los evangelios sinópticos ${ }^{65}$. Por ello he preferido incluir el uso del término en este Evangelio en un epígrafe distinto y comentarlas una a una.

En el cuarto Evangelio se da un cambio en el concepto de mesianismo: de la noción puramente judía de «hijo de David» guerrero, hasta el Hijo del hombre, juez futuro y, además, divino ${ }^{66}$. En palabras de Fernández Ramos, «el evangelista utiliza al Hijo del hombre como medio para armonizar (...) la escatología tradicional, vinculada al "apocalíptico" Hijo del hombre, y la escatología existencial, vivencial, realizada ya en parte, aunque caminando todavía hacia la consumación ${ }^{67}$ \%.

La primera de ellas habla de la parusía y de la fe que se necesita para esperar su llegada. el Hijo del hombre aparece aquí como un apoyo sobre el que poder ascender al cielo prometido: Jn 1,51.

Este sentido escatológico se sigue apreciando en la siguiente cita, pero se nos indica el origen del Hijo del hombre y su ascenso a los cielos al final; también se ha interpretado la «elevación» como uaticinium ex euentu de la crucifixión de Jesús y, al mismo tiempo, de su glorificación: Jn 3,13-15.

En el juicio final, será el Hijo del hombre el que juzgue, gracias al poder que le dio Dios Padre: Jn 5,26-27.

La vida eterna no es algo del todo gratuito, es algo que debe ganarse con esfuerzo, como el alimento terreno: Jn 6,27.

Enlazado con el sentido del alimento imperecedero, está la institución de la Eucaristía como medio de alcanzar la vida eterna: Jn 6,53-55.

En la siguiente cita, aunque algo complicada de entender, parece claro el carácter autorreferencial de Hijo del hombre, ya que lo equipara a «yo soy»; al igual que ocurría con Jn 3,13-15, en ocasiones se ha interpretado la «elevación» como uaticinium ex euentum: Jn 8,28.

En la narración de la curación del ciego, también queda patente la identificación personal de Jesús con el Hijo del hombre, ya que es el que tiene delante el ciego cuando puede ver: Jn 9,35-37.

La siguiente cita puede entenderse como un anuncio de la pasión, en la línea de lo que comentábamos en el epígrafe 8.4: Jn 12,23.

Los contemporáneos de Jesús tenían una idea más o menos clara de lo que era la figura del Mesías y, lógicamente, trataron de enlazarlo con la idea que propagaba del Hijo del hombre: Jn 12,34.

La traición de Judas supone el comienzo de la pasión de Jesús y, por tanto, de su posterior resurrección y su parusía: Jn 13,31.

Como se ha podido comprobar, todas las apariciones de la expresión en el cuarto Evangelio - excepto 9,35-37- hacen referencia, de una u otra manera, a la glorificación de Jesús, a la metáfora de la elevación con el doble significado: por una parte, la izada de la cruz, la presunta derrota de Jesús ante la muerte y, por otra parte, la glorificación, el ascenso a los cielos del resucitado y el reconocimiento por parte

Fernández Ramos 2001, s.v. Hijo del hombre.

Piñero 2006, 401.

67 Fernández Ramos, 2001, s.v. Hijo del hombre. 
de Dios Padre. La otra aparición, ya citada y comentada, es un caso evidente de autorreferencia, por lo que guarda el sentido original de la expresión aramea.

\section{Conclusión}

Los autores de los evangelios no conocieron a Jesús; de hecho, pertenecían a la generación posterior e incluso, como es probable en el caso del autor del cuarto evangelio, a dos generaciones después de la de Jesús. Esto, que podría parecer una obviedad, debe ser recordado aquí, porque nos hace ver que los evangelistas no fueron testigos directos de las palabras y las acciones de Jesús, sino que escribieron lo que otros les contaron que habían escuchado y vivido.

De este hecho se derivan unas consecuencias que resultan importantes: por un lado, en ningún momento se nos explica qué significa Hijo de hombre y, además, como ya hemos visto (vid. 8.1), no hay constancia tampoco de que la expresión despertara ni entusiasmo ni hostilidad ni extrañeza. Resulta difícil no deducir de esto que la expresión era, si no de uso común, sí fácilmente comprensible. Esto no debería parecernos extraño si reflexionamos en lo que ocurre en la actualidad con la alocución: la traducción habitual en español es «el Hijo del hombre», con los dos artículos, mientras que en inglés se dice «Son of man», sin artículos. No cabe duda de que el concepto es el mismo y, al tiempo, es fácilmente comprensible por lectores de ambos idiomas, pero la expresión se ha adaptado al sistema gramatical de cada lengua. Algo parecido debió pasar en la época de Jesús: probablemente muchos de sus contemporáneos eran bilingües; aunque hablantes nativos de arameo, también se defenderían con el griego. Y lo que es evidente es que el griego era el vehículo de cultura y, por lo tanto, de escritura. Y más aún, los evangelios se escriben para un público conocedor del griego.

Tras lo que hemos visto, resulta más que probable que Jesús se refiriera a sí mismo como Hijo del hombre, con el sentido autorreferencial que tiene el término en arameo. Posteriormente, los autores de los evangelios, grecoparlantes y, además, conocedores del libro de Daniel en la versión inserta en la Septuaginta, enlazaron, por una parte, el mensaje apocalíptico crucial que aparece en Daniel 7,13, con la venida de «uno como Hijo de hombre», identificado desde el primer momento como el Mesías prometido y liberador, y, por otra, el uso trivial y cotidiano en arameo de la expresión autorreferencial y dieron lugar a la interpretación de «el Hijo del hombre» como título salvífico o mesiánico.

Evidentemente, el aceptar que el título Hijo del hombre procede de un libro que pertenece a la literatura apocalíptica judía, pasando además por sus «secuelas» en 1 Henoc y 4 Esdras, daría un argumento a los que afirman que, en realidad, el nacimiento del cristianismo se inserta dentro del conjunto de movimientos apocalípticos que, en esta época, se van fraguando dentro de la historia de la religión de Israel. Por el contrario, la ausencia de certeza sobre si Jesús utilizaba de manera habitual la expresión autorreferencial «Hijo del hombre» y nuestro desconocimiento de si esta expresión iba intencionalmente ligada a la cita del Libro de Daniel, no nos permite afirmar de manera contundente que Jesús fuera un profeta esencialmente apocalíptico. 


\section{Bibliografía}

E. Adams, «The Coming of the Son of Man in Mark's Gospel», Tyndale Bulletin 56 (2) (2005) 39-61.

R. Bultmann, Teología del Nuevo Testamento, Salamanca, 1981.

D. Burkett, The Son of Man Debate. A History and Evaluation, Cambridge, 2004.

F. Cantera y M. Iglesias, Sagrada Biblia, Madrid, 1975².

J. J. Collins, «The Son of Man in First-Century Judaism», NTS, 38 (3) (1992) 448-66.

J. J. Collins, Daniel: A commentary on the Book of Daniel, Minneapolis, 1993.

J. J. Collins, The Apocalyptic Imagination, Cambridge, $1998^{2}$.

J. J. Collins, The Scepter and the Star: Messianism in Light of the Dead Sea Scrolls, Cambridge, 2010.

J. Corley, «Judith», en J. K. Aitken (ed.), The T\&T Clark Companion to the Septuagint, London-New York (2015) 222-36.

F. Corriente y A. Piñero, «Libro 1 de Henoc», en A. Díez Macho (ed.), Apócrifos del Antiguo Testamento 4, Madrid (1984).

J. D. Crossan, The Historical Jesus: The Life of a Mediterranean Jewish Peasant, San Francisco, 1991.

A. Díez Macho, Apócrifos del Antiguo Testamento, Vol. 1, Madrid, 1982.

C. H. Dodd, According to the Scriptures: The Substructure of New Testament Theology, London, 1952.

J. D. G. Dunn, «The Danielic Son of Man in the New Testament», en The Book Of Daniel, Vol. II, Composition and Reception, Leiden-Boston-Köln (2001) 528-549.

B. D. Ehrman, The Apostolic Fathers, Vol. 1, Cambridge-London, 2003.

E. Evans, Tertullian. Adversus Marcionem, Vol. 2, Oxford, 1972.

N. Fernández Marcos, y M. V. Spottorno, La Biblia griega. Septuaginta, Salamanca, 20082015.

D. Flusser, Jesus, New York, 1969.

M. de Jonge, Jesus: Stranger from Heaven and Son of God. Jesus Christ and the Christians in Johannine Perspective, Atlanta, 1977.

G. D. Kirchhevel, «The «Son of Man» Passages in Mark», Bulletin for Biblical Research 9 (1999) 181-87.

A. A. di Lella, «The Textual History of Septuagint-Daniel and Theodotion-Daniel», en John J. Collins (ed.), The Book of Daniel. Composition and Reception Vol. 2, Leiden (2001) 586-607.

D. Muñoz León, «Libro IV de Esdras», en A. Díez Macho y A. Piñero (eds.), Apócrifos del Antiguo Testamento Vol. 6, Madrid, (2009).

C. Naseri, y M. Naseri, «Jesus as the Son of Man in the Gospels: An Interpretation», American Journal of Social Issues and Humanities 3 (4) (2013), 189-99.

X. Pikaza, Hijo de hombre. Historia de Jesús Galileo, Valencia, 2007.

A. Piñero, Guía para entender el Nuevo Testamento, Madrid, 2006.

S. E. Porter, «Dating the Composition of New Testament Books and Their Influence upon Reconstructing the Origins of Christianity», en I. Muñoz Gallarte y J. Peláez del Rosal (eds.) In mari via tua. Philological Studies in Honour of Antonio Piñero, Córdoba (2016) 553-574.

B. E. Reynolds, «The «One Like a Son of Man» According to the Old Greek of Daniel 7,1314», Biblica 89 (2008) 70-80.

N. Russell, Daniel, Westminster, 1981. 
N. Russell, Doctrine of the Deification in the Greek Patristic Tradition, London, 2005.

E. P. Sanders, The Historical Figure of Jesus, Harmondsworth, 1993.

J. Schröter, «The Gospel of Mark», en Aune, D. E. (ed.), The Blackwell Companion to the New Testament, West Sussex (2010) 272-295.

M. B. Shepherd, «Daniel 7:13 and the New Testament Son of Man», Westminster Theological Journal 68 (2006) 99-111.

A. A. Tejada-Lalinde, Jesus as the Son of Man in Mark, Paper 1175: FIU Electronic Theses and Dissertations, 2014.

G. Theissen y A. Merz, El Jesús histórico, Salamanca, 1999.

G. Vermes, Jesús el Judio. Los Evangelios leídos por un historiador, Barcelona, 1977.

H. Wilson, «A Survey of the «Son of Man» from Daniel to Jesus, Part 1: A Reevaluation of Daniel 7 and Its Subsequent Implications on the «Son of Man» Debate», Studia Antiqua 14 (2) (2016) 1-26.

B. Witherington III, The Christology of Jesus, Minneapolis, 1990.

A. Yarbro Collins, Cosmology and eschatology in Jewish and Christian apocalypticism, Leiden-New York-Köln, 1996.

A. Yarbro Collins y J. J. Collins, King and Messiah as Son of God. Divine, Human, and Angelic Messianic Figures in Biblical and Related Literature, Grand Rapids-Cambridge, 2008.

J. Ziegler y O. Munnich, Septuaginta: Vetus Testamentum Graecum Auctoritate Scientiarum Gottingensis Editum XVI, 2: Susanna Daniel Bel Draco, Göttingen, 1999. 